Available online at JECE (Journal of Early Childhood Education)

Website: http://journal.uinjkt.ac.id/index.php/jece

Permalink/DOI: http://dx.doi.org/10.15408/jece.v1i2.13278

JECE, 1 (2), Desember 2019, 1-8

\title{
PERMAINAN KOLASE UNTUK MENINGKATKAN MOTORIK HALUS PADA KELOMPOK A TK MUSLIMAT NU BANJARMASIN
}

\author{
Huda, Ratna Faeruz, Miratul Hayati \\ Universitas Islam Negeri Syarif Hidayatullah Jakarta \\ corresponding e-mail: ratnaf@uinjkt.ac.id
}

\begin{abstract}
The purpose of this study was to improve children's fine motor skills through collage play in groip A at Muslimat NU Banjarmasin Kindegarten. This research is collaborative classroom action research using Kemmis and Mc Taggart model. The subjects of the study are 10 children in group A at Muslimat NU Kindergarten. The object of this study is the children's fine motor skill. Guided observation is used for this instrument. The data analysis technique is carried out qualitatively and quantitatively. This research was conducted in two cycles. The result shows a gradual increase in children's fine motor skills. Improvement of children's fine motor skill through collage play in the implementation of pre-liminary research $40,45 \%$ and in the first cycle increased to 50,59\%. In $2^{\text {nd }}$ cycle, the child's fine motor ability increased with percentage $80,68 \%$.
\end{abstract}

Keywords : fine motor skills, collage games, kindergarten

\begin{abstract}
Abstrak
Tujuan dari penelitian ini adalah untuk meningkatkan kemampuan motorik halus anak melalui bermain kolase pada kelompok A di TK Muslimat NU Banjarmasin. Penelitian tindakan kelas kolaboratif dengan menggunakan model Kemmis dan Mc Taggart digunakan dalam penelitian ini. Terpilih sebagai subjek penelitian adalah anak TK Muslimat NU Kelompok A berjumlah 10 anak. Instrumen yang digunakan adalah pedoman observasi. Teknik analisis data dilakukan secara kualitatif dan kuantitatif. Untuk dapat mengamati perubahan atas tindakan yang dilakukan, penelitian ini menerapkan dua siklus. Setelah dilakukan tindakan melalui dua siklus diperoleh hasil bahwa bermain kolase dapat meningkatkan kemampuan motorik halus anak dengan persentase kenaikan $40,45 \%$ saat pratindakan yang kemudian meningkat pada siklus I menjadi 51,59\%. Selanjutnya setelah dilakukan siklus II, kemampuan motorik halus anak meningkat dengan persentase 80,68\%.
\end{abstract}

Kata Kunci: kemampuan motorik halus, permainan kolase, taman kanak-kanak 


\section{Pendahuluan}

Dalam rangka menunjang pertumbuhan dan perkembangan jasmani dan rohani anak, maka perlu diselenggarakan pendidikan anak usia dini yang memperhatikan seluruh aspek tumbuh kembang anak. Seluruh aspek perkembangan meningkat secara fundamental dan optimal pada anak usia dini, salah satunya adalah perkembangan motorik.

Perkembangan motorik merupakan salah satu aspek perkembangan yang penting dalam perkembangan individu secara keseluruhan. Perkembangan motorik memiliki pengaruh antara lain: a) seorang anak bisa mendapatkan rasa senang manakala dia bisa mengoptimalkan kerja-kerja motoriknya melalui berbagai permainan dan aktivitas motorik halus maupun motorik kasar lainya. Dari proses bermain tersebut anak akan mendapatkan pengalaman-pengalaman baru yang menyenangkan sekaligus menstimulus perkembanagn, kognitif, emosional, sosial dan spiritualnya terlebih jika dilakukan dengan teman sebayanya. b) dengan ditunjang keterampilan motorik yang baik, memungkinkan anak untuk dapat lepas dari ketidakberdayaan pada fase-fase awal kelahiranya kepada kondisi yang lebih mandiri (independent). Kepercayaan diri anak akan perlahan tumbuh dengan gerakan-gerakan motorik dari satu tempat ketempat lainya. c) kemampuan anak menyesuaikan diri dengan lingkungan sekolah sepertik aktifitas melukis, menulis dan menggambar akan sangat terbantu dengan berkembangnya kemampuan motorik anak. d) perkembangan kemampuan motorik yang baik akan memungkinkan anak untuk bermain dan berinteraksi dengan yang lainya sehingga menunjang perkembangan sosial dan emosionalnya. Sebaliknya jika karena kemampuan motoriknya tidak mendukungnya untuk bermain dan bergaul dengan teman sebayanya, maka sangat mungkin seorang anak terkucil. e) Perkembangan kepribadian anak akan makin baik jika dapat ditunjang dengan perkembangan keterampilan motorik. (Hurlock, 1980)

Kemampuan motorik halus adalah salah satu perkembangan motorik yang harus dioptimalkan karena menjunjang banyak sekali perkembangan lainya pada diri anak. Cratty (dalam Samsudin, 2008) berpendapat bahwa motorik halus berkaitan dengan kematangan mekanisme otot syaraf yang memberikan penampilan progresif pada keterampilan motorik, seperti kegiatan literasi dan berbagai kegiatan akademik lainnya, agar anak memiliki kesiapan dalam memasuki pendidikan lebih lanjut. Berlener (dalam Anggani, 2000) mengatakan motorik halus adalah keadaan yang menunjukkan kemampuan mengunakan media tertentu melalui koordinasi antara mata dan tangan. Karenanya gerakan tangan dengan mata harus terus dikembangkan secara optimal sehingga keterampilan yang mendasar seperti membuat garis horizontal (_), membuat garis vertikal $(|| \mid)$, membuat garis miring kiri $(\backslash \backslash \backslash$ ) atau kanan $(/ / /)$, membuat garis lengkung (c), ataupun membuat lingkaran (oo) mampu meningkat secara terus menerus. 
Perkembangan motorik halus menjadi sangat penting untuk melatih gerak otot dan koordinasi tangan dan mata agar kemampuan dan kerapian anak sesuai dengan tahap perkembangan usianya. Pada saat anak berada pada usia prasekolah, merupakan waktu yang tepat untuk melatih kemampuan seperti menggambar, menggunting dan menulis, karena pada usia 4-5 tahun anak mampu memegang alat tulis secara tripod grasp dan menulis sesuai dengan contoh yang telah diberikan atau coretan bebas dari anak yang membutuhkan ketekunan dan keuletan (Anggani, 2005).

Bermain mempunyai peran yang sangat penting dalam peningkatan kemampuan motorik halus anak, Dworetsky (dalam Moeslichaton, 2004) menjelaskan bermain merupakan kegiatan yang dilakukan berulang ulang dan menimbulkan perasaan senang yang mana lebih menekankan pada prosesnya dari pada hasilnya. Kegiatan bemain juga merupakan kegiatan yang menyenangkan, sehingga bermain merupakan cara belajar yang efektif bagi anak. Melalui bermain terjadi stimulasi pertumbuhan otot dan otak anak. Melalui bermain anak dapat berekspresi dan melakukan eksplorasi sehingga dapat memantabkan berbagai hal yang telah mereka ketahui serta menemukan hal baru. Terkait dengan perkembangan potensi diri yang dimiliki anak, bermain dan permainan dapat membantu secara optimal seluruh potensi yang ada seperti potensi fisik, mental intelektual dan moral sprititual.

Joan (dalam Yus, 2011) mengatakan, bahwa bermain adalah "aktivitas yang dapat membantu anak mencapai tahapan perkembangan yang utuh, baik fisik, intelektual, sosial, moral dan emosional". Bermain dapat memberikan efek positif terhadap perkembangan anak. Bermain dapat membantu anak menyerap berbagai hal baru dari lingkungan tumbuh kembangnya. Pada saat anak bermain semua aspek perkembangan anak terstimulus dan berkembang dengan baik. Piaget (dalam Mayestik, 2011) berpendapat bahwa bermain merupakan suatu aktivitas yang dapat memberikan kesenangan dan kepuasan bagi diri anak sehingga mereka dapat melalukannya secara berulang. Sementara itu Fleer (dalam Nurani, 2013) mengatakan "kegiatan bermain dapat membantu anak mengenal tentang diri sendiri, dengan siapa ia hidup serta lingkungan tempat dimana ia hidup. Menurutnya bermain dapat menjadi sarana sosialisasi, bereksplorasi, menemukan, berekspresi, berkreasi, dan belajar dengan menyenangkan".

Permainan kolase dapat meningkatkan kreativitas anak (Devi, 2014) peneliti melakukan permainan kolase dengan menggunakan bahan alam dengan melibatkan anak untuk melakukan kegiatan menggunting, menyobek, memotong dan menggulung bahan sesuai dengan keinginan anak, mampu meningkatkan kemampuan kreativitas anak hingga 81, 25\%. (Fratnya Puspita Devi, 2014). Penelitian ini diperkuat oleh penelitian yang dilakukan Nia sutisna dan Yeni bahwa permainan kolase mampu meningkatkan kemampuan motorik halus pada siswa 
Celebral Palsy tipe spastik. Hal ini terbukti dengan adanya peningkatan kemampuan motorik halus pada anak celebral Palsy tersebut sebanyak 85, 29\% (Sutisna dan Rachmawati, 2018).

Kolase merupakan kegiatan seni yang dilakukan dengan menempelkan benda tertentu (biji-bijian, kaca, kayu, dll) ke sebuah area yang telah disediakan untuk membentuk suatu bentuk tertentu. Anak-anak sangat senang dengan aktifitas ini karena mereka dapat meletakkan dan menempelkan di area tertentu yang telah disediakan sesuai dengan bentuk dan pola yang mereka inginkan. Seefeld dan Wasik (dalam khasanah, 2019) mengatakan hal yang sama bahwa seni kolase dengan karakteristik produknya yang bermotif tertentu, praktis dan relatif cepat dikerjakan, sangat disukai oleh anak-anak terlebih menimbulkan kesan tiga dimensi. Permainan kolase merupakan salah satu permainan yang banyak melibatkan penggunaan motorik halus dalam kegiatanya. Sehingga harapanya melalui bermain kolase kemampuan motorik halus anak mampu berkembangn secara optimal.

\section{Metode}

Penelitian ini bertujuan untuk mengetahui implementasi permainan kolase dalam meningkatkan kemampuan motorik halus pada anak kelompok A di TK Muslimat NU Banjarmasin dan peningkatan kemampuan motorik halus pada anak kelompok A di TK Muslimat NU Banjarmasin setelah diterapkannya permainan kolase.

Penelitian ini dilaksanakan di TK Taman Kanak-Kanak Muslimat NU Banjarmasin Kalimantan Selatan dengan subjek anak usia 4-5 Tahun yaitu pada siswa Taman Kanak-Kanak Kelompok A dengan jumlah siswa sebanyak 10 anak yang beralamat Jalan Pekapuran B Laut Banjarmasin. Waktu penelitian dilaksanakan pada bulan November 2018. Penelitian ini menggunakan Penelitian Tindakan Kelas (Kemmis \& Taggart, 2002) Metode yang digunakan adalah Mix Method yang menggunakan kedua pendekatan kuantitatif dan kualitatif yang dilakukan secara kolaboratif yaitu adanya kerjasama semua pihak di dalamnya guru, kepala sekolah, dan teman sejawat. Subyek Penelitian Tindakan Kelas adalah Kelompok A TK Muslimat NU Banjarmasin, metode pengumpulan data dilakukan melalui observasi, dokumentasi dan wawancara. Penelitian ini menggunakan model Kemmis dan Taggart, yang terdiri dari tahapan: perencanaan, pelaksanaan, observasi, dan refleksi.

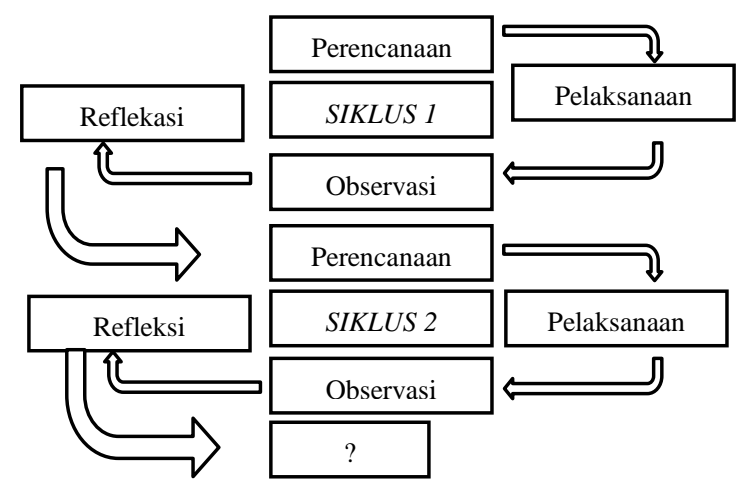

Vol. 1 No. 2 |4-8

Copyright (C) 2019 | JECE | P-ISSN 2686-2492 
Gambar 3.1 Siklus Penelitian Tindakan Kelas (PTK)

Indikator keberhasilan dalam penelitian ini adanya peningkatan kemampuan motorik halus anak di TK Muslimat NU Banjarmasin. Subjek dari penelitian tersebut adalah untuk anak usia 4-5 tahun. Pemilihan 10 anak karena dari hasil penelitian awal kemampuan motorik halus anak TK A masih harus ditingkatkan. Dalam PTK ini, peneliti menentukan sendiri standar dan patokanya yang memperhatikan kemampuan subjek penelitian. Adapun kriterian peniliaan ditentukan empat skala yaitu sangat baik, baik, cukup, dan sangat kurang. Selanjutnya peneliti menentukan intepretasi target keberhasilan yang diharapkan mencapai $\geq 75 \%$. Untuk mendapatkan hasil tersebut peneliti menyusun instrumen pengamatan anak dan menerapkan siklus satu yang terdiri dari enam pertemuan, dan siklus dua yang terdiri atas enam pertemuan.

\section{Hasil dan Pembahasan}

Data hasil penelitian tindakan yang dilakukan dari kegiatan pra-siklus, siklus 1 dan siklus 2 dijelaskan pada table di bawah ini:

Tabel.1

Data Awal Pra-Tindakan dan Akhir Setelah Tindakan Kemampuan Motorik Halus Subjek Penelitian

\begin{tabular}{|c|c|c|c|c|c|c|c|c|c|c|c|}
\hline \multicolumn{2}{|c|}{ Subjek } & \multicolumn{2}{c|}{ Pratindakan } & \multicolumn{2}{c|}{ Siklus 1} & \multicolumn{2}{c|}{ Poin Siklus 2} & \multicolumn{2}{c|}{ Poin } \\
\hline No. & Nama & Skor & $\%$ & Skor & $\%$ & Kenaikan & $\%$ & Skor & $\%$ & Kenaikan & $\%$ \\
\hline 1 & AR & 16 & 36,36 & 21 & 47,72 & 5 & 11,36 & 35 & 79,55 & 14 & 31,82 \\
\hline 2 & JS & 16 & 36,36 & 19 & 43,18 & 3 & 6,818 & 33 & 75 & 14 & 31,82 \\
\hline 3 & KA & 20 & 45,45 & 28 & 63,63 & 8 & 18,18 & 40 & 90,91 & 12 & 27,27 \\
\hline 4 & MA & 17 & 38,36 & 23 & 52,27 & 6 & 13,64 & 37 & 84,09 & 14 & 31,82 \\
\hline 5 & MF & 19 & 43,18 & 23 & 52,27 & 4 & 9.09 & 34 & 77,27 & 11 & 25 \\
\hline 6 & MM & 20 & 45,45 & 22 & 50 & 2 & 4,54 & 34 & 77,27 & 12 & 27,27 \\
\hline 7 & MY & 21 & 47,72 & 23 & 52,27 & 2 & 4,54 & 36 & 81,82 & 13 & 29,55 \\
\hline 8 & NA & 18 & 40,90 & 23 & 52,27 & 5 & 11,36 & 35 & 79,55 & 12 & 27,27 \\
\hline 9 & RN & 11 & 25 & 17 & 38,63 & 6 & 13,64 & 33 & 75 & 16 & 36,36 \\
\hline 10 & SN & 20 & 45,45 & 28 & 63,63 & 8 & 18,18 & 38 & 86,36 & 10 & 27,73 \\
\hline \multicolumn{2}{|l}{ Jumlah } & 178 & 40,45 & 227 & 51,59 & 49 & 11,14 & 355 & 80,68 & 128 & 29,09 \\
\hline
\end{tabular}

Tabel di atas menunjukan peningkatan kemampuan motorik halus anak setelah melalui tindakan yang direncanakan dalam dua siklus penelitian ini. Pada siklus I didapatkan kemampuan motorik anak mengalami peningkatan rata-rata sekitar $11,14 \%$. Selanjutnya ketika dilaksanakan tindakan dalam siklus II didapati kenaikan kemampuan motorik halus anak sebesar rata-rata 29,09\% dari siklus I. Indikasi keberhasilan perlakuan (tindakan) dalam penelitian ini dapat diamati melalui peningkatan kemampuan motorik halus anak dalam bermain kolase pada kelompok A. Hasil penelitian ini menunjukkan bahwa bermain kolase dapat meningkatkan kemampuan motorik halus anak kelompok A. Setelah dilakukan dua kali tindakan, dapat dibuktukan kemampuan motorik halus anak mengalami peningkatan yang 
cukup signifikan. Skor yang diperoleh subjek penelitian menunjukan peningkatan kemampuan motorik halus setelah melalui dua siklus dan dilakukan observasi secara teliti. Ini dibuktikan dengan adanya prosentase anak yang paling rendah kemampuan motorik halusnya yaitu $4,54 \%$ pada pra-perlakukan kemudian meningkat menjadi $29,55 \%$ sehingga persentase kemampuan motorik halus seluruh subjek penelitian dalam kelompok A mencapai $80,68 \%$ pada akhir siklus.

Data kualitatif yang dapat diperoleh dalam penelitian tindakan ini adalah sebagai berikut:

1) Proses pembelajaran

a) Dalam menyusun proses pembelajaran, ada beberapa tahapan yang harus dilakukan oleh seorang guru salah satunya perencanaan pembelajaran sehingga dapat menjadikan proses pembelajaran menjadi menarik dan menyenangkan serta lebih mudah untuk dipahami peserta didik dalam permainan kolase. Pembelajaran tersebut tidak sebatas hanya menyenangkan, tetapi juga dapat memotivasi anak untuk lebih kreatif dan menambah kepercayaan diri pada anak.

b) Anak tampak antusias dan semangat karena belajar melalui permainan yang mereka sukai yaitu kolase yang dapat membuat anak berimajinasi sesuka hati mereka dalam menempel-nempel dan menggambar bebas. Perkembangan kemampuan motorik halus anak melalui permainan kolase berlangsung secara bertahap, yaitu mulai anak mampu menempel kolase yang meliputi merobek kertas untuk bahan kolase, mengambil potongan kertas, memegang lem dengan jari tangan, membersihkan tangan setelah menggunakan lem, menulis nama sendiri pada lembar kolase, bermain kolase sesuai aturan serta menggambar bebas.

2) Media pembelajaran

Media pembelajaran yang dirancang sesuai dengan perkembangan anak dan kebutuhan anak terutama pada kelompok A yaitu media yang bervariasi baik warna dan bentuk, dan alat yang berkaitan dengan meningkatkan kemampuan motorik halus.

3) Kemampuan Motorik Halus Anak

Berdasarkan hasil pengamatan/observasi menunjukkan terdapat peningkatan kemampuan motorik halus anak yang meliputi aspek gerakan tubuh yang terkoordinasi antara mata dan tangan, koordinasi bilateral, keterampilan manipulasi tangan dan tripod grasp. Hal tersebut ditunjukan melalui hasil pengamatan dalam proses pembelajaran, kemampuan motorik halus anak yang terdapat rekaman, foto, catatan lapangan dan catatan wawancara. Secara kualitatif, berdasarkan penyusunan data menurut Miles dan Huberman, tahapan 
yang dilalui yaitu reduksi data, display data, dan verifikasi (penarikan kesimpulan).

\section{Simpulan}

Sebagaimana telah dikemukakan dalam pembahasan penelitian tindakan diatas, dapat disimpulkan bahwa bermain kolase dapat meningkatkan kemampuan motorik halus anak pada kelompok A TK Muslimat NU Banjarmasin. Hal ini terindikasi melalui peningkatan persentase kemampuan anak hasil pengukuran sebelum maupun setelah tindakan. Hal tersebut dapat dilihat ketika pra-penelitian di peroleh persentase sebesar $40,45 \%$ kemudian pada siklus 1 rata-rata persentase menjadi $51,59 \%$. Pada siklus 1 sudah terjadi peningkatan namun belum memenuhi kriteria keberhasilan sebesar $75 \%$, sehingga dilakukan siklus II dan presentase ratarata menjadi $80,68 \%$. Adapun indikator peningkatan motorik halus bisa dilihat dari berbagai aspek kemampuan motorik halus anak yaitu gerakan koordinasi antara mata dan tangan, koordinasi bilateral, kemampuan manipulasi tangan dan tripod grasp.[]

\section{Daftar Rujukan}

Alfiah. (2014). “Upaya Meningkatkan Kemampuan Motorik Halus Dalam Memegang Alat Tulis Melalui Kegiatan Menggambar Dengan Media Kapur Tulis Dan Arang Pada Siswa", Vol. 2, No. 2.

Devi, Fratnya Puspita. (2014). “Peningkatan Kreativitas Melalui Kegiatan Kolase Pada Anak Kelompok B2 Di TK Aba Keringan Kecamatan Turi Kabupaten Sleman", Tesis, Universitas Negri Yogyakarta: Fakultas Ilmu Pendidikan.

Diana, Mutiah. (2010). Psikologi Bermain AUD. Jakarta: Kencana.

Ema, Yohana. (2013). Meningkatkan Kreativitas Anak dengan Teknik Mozaik Dengan Media Biji-bijian. Bengkulu: UNIB.

Guyton \& Hall. (2008). Buku Ajar Fisiologi Kedokteran. Jakarta: EGC.

Hajar, Pamadhi dan Evan Sukard. (2010). Seni Keterampilan Anak. Jakarta: UT.

Hurlock, Lizabeth. (1980). Psikologi Perkembangan Suatu Pendekatan Sepanjang Rentang Kehidupan Edisi Kelima. Jakarta: Erlangga.

Khasanah, Yuli Nur. (2019). “Meningkatkan kretivitas melalui kegiatan Kolase pada anak", Golden Age Jurnal Ilmiah Tumbuh Kembang Anak.

Kurnia, Selia Dwi. (2015). "Pengaruh Kegiatan Painting dan Ketrampilan Motorik Halus Terhadap Kreativitas AUD Dalam Seni Lukis", Jurnal PAUD, Vol. 9, No. 2. 
Latif, Mukhtar. (2013). Orientasi Baru PAUD Teori dan Aplikasi. Jakarta: Kencana. Mayesky. (2011). Perkembangan Anak II. Jakarta: PT Indeks.

Moeslichatoen. (2004). Metode pengajaran di taman kanak-kanak. Jakarta: Rineka Cipta.

Nurani, Yuliani. (2013). Konsep Dasar Pendidikan PAUD. Jakarta: Indeks.

Samsudin. (2008). Pembelajaran Motorik di Taman Kanak-Kanak. Jakarta: Litera.

Santrock. (2007). Perkembangan Anak. Jakarta: Erlangga.

Sumanto. (2005). Pengembangan Kreativitas Senirupa Anak TK. Jakarta: Depdikbud.

Sutisna, Nina., dan Yeni Rachmawati. (2018). Pengaruh Aktivitas Kolase Terhadap Peningkatan Kemampuan Motorik Halus Pada Siswa Cerebral Palsy Tipe Spastik. Bandung : Pedagogia.

Sudono, Anggani. (2000). Sumber Belajar dan Alat Permainan. Jakarta: Grasindo.

Yus, Anita. (2011). Penilaian Perkembangan Belajar Anak. Jakarta: Kencana. 